\title{
Breaking Capacity Test of 126kV/2500A/40kA Double Breaks Vacuum Circuit Breaker
}

\author{
Xie Jiuming $^{1,2}$, Sun Dengyue ${ }^{1}$, Wang Peng ${ }^{3}$, Wang Jianzhong ${ }^{2}$ and Ji Hai ${ }^{2}$ \\ ${ }^{1}$ National Engineering Research Center for Equipment and Technology of Cold \\ Strip Rolling, Yanshan University, Qinhuangdao, 066004 \\ ${ }^{2}$ Central Research Institute of Tianjin Benefo Machinery Equipment Group Co., \\ LTD, Tianjin, 300350 \\ ${ }^{3}$ Tianjin Light Industry Vocational Technical College, Tianjin, 300350 \\ xjmzxt@126.com
}

\begin{abstract}
High-voltage vacuum circuit breakers are intended for breaking the short-circuit current, and the breaking capacity is the major performance indicator. In the paper, the Weil synthetic circuit was built, and by using unit testing method and referring to standard GB/T 1984-2014, the breaking capacity of 126kV/2500A/40kA double-break vacuum circuit breaker developed by Central Research Institute of Tianjin Benefo Machinery Equipment Group Co., LTD was tested. Result showed that this vacuum circuit break can meet the breaking capacity requirement for grid integration
\end{abstract}

Keywords: $126 \mathrm{kV}$ vacuum circuit breaker, breaking capacity, Weil synthetic circuit, breaking capacity test

\section{Introduction}

High-voltage circuit breakers play the double roles of controlling the operation of the grid and safeguarding the safety of the grid. When the grid operates normally, the operation mode of the grid can be switched by connecting to or separating the devices from the circuit via the circuit breakers; in case of fault, circuit breakers can quickly detect it and interrupt the circuit, so that the circuit is safely protected. The breaking capacity of the circuit breaker is the guarantee of the safe operation of the grid system.

However, the problems that the breaking capacity refer to is very complex and so far we have no established theories and quantification method to measure it. Therefore, the performance can be only evaluated through testing.

Here he test for the breaking capacity of $126 \mathrm{kV} / 2500 \mathrm{~A} / 40 \mathrm{kA}$ double-break vacuum circuit breakers developed by Central Research Institute of Tianjin Benefo Machinery Equipment Group Co., LTD was performed.

\section{Overall Design of the Breaking Capacity Test}

The widely used method for testing the breaking capacity of vacuum circuit breakers is the synthetic testing circuit, which has been described in the International Electrical Commission (IEC) standards.

The breaking capacity test was carried out at Institute of Power Electronics, Dalian University of Technology. The capacity class of the Weil synthetic testing circuit was $50 \mathrm{kA} / 72.5 \mathrm{kV}$, and the recovery voltage was $72.5 \mathrm{kV}$. We made some modifications of the Weil synthetic circuit based on previous test results so that it would meet the requirements for unit testing method. The testing conditions met the requirement on unit testing method 
in standard GB/T 4473-2008, and the actual breaking capacity of the $126 \mathrm{kV}$ double-break vacuum circuit breaker in interrupting the short-circuit current was evaluated.

It is stipulated in standard GB/T 4437-2008 that the unit testing method should satisfy the following requirements:

(1) Each break is installed with vacuum arc extinguishing chamber with uniform shape, size, performance and type.

(2) The same type of permanent magnetic actuator is to be used for independent manipulation of the double breakers, and the good consistency in the speed of opening and closing the switch should be ensured.

(3) The vacuum arc extinguishing chambers between the breaks should be mutually independent so that the breaking capacity of the circuit breaker as a whole can be evaluated by examining the short-circuit current breaking performance of either break.

The $126 \mathrm{kV} / 2500 \mathrm{~A} / 40 \mathrm{kA}$ circuit breaker under evaluation completely satisfied the above requirement in standard GB/T 4437-2008, so the unit testing method was adopted.

\section{Overall Design of Weil Synthetic Circuit}

The diagram of Weil synthetic testing circuit after some modifications is shown in Figure 1 .

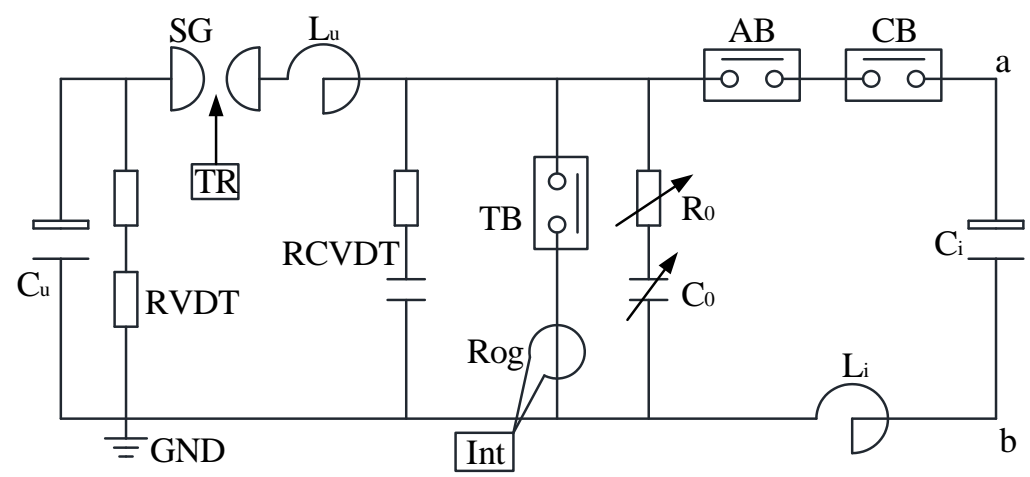

\section{Figure 1. The Diagram of The Weil Synthetic Testing Circuit}

The Weil synthetic circuit is composed of three parts, namely, hardware system, control system and communication system. The hardware system comprises voltage source circuit, current source circuit and other electronic components. The control system comprises PLC and circuit board, and optical fiber is used for transmitting the trigger signals for the spark spherical gap. In this way, the accuracy, controllability and on-line monitoring of current source and the time of the input of voltage source are ensured. This synthetic circuit is the current source circuit. At several hundreds of microseconds before zero crossing, the voltage source is input into the arc gap, thus ensuring that the shortcircuit current is the sine wave without current distortion. The actual breaking in the grid was simulated in the test so as to achieve equivalence.

In this circuit, both the voltage source and the current source are LC oscillator circuits. The voltage source is on the left, and the current source is on the right. The name and function of the components are shown in Table 1 . 
Table 1. Name and Function of Components

\begin{tabular}{|c|c|c|c|}
\hline Symbol & Name & \multicolumn{2}{|c|}{ Function } \\
\hline $\mathrm{C}_{\mathrm{u}}$ & $\begin{array}{l}\text { Capacitor of } \\
\text { voltage source }\end{array}$ & - & \\
\hline $\mathrm{L}_{\mathrm{u}}$ & Inductor & - & \\
\hline $\mathrm{R}_{0}$ & $\begin{array}{l}\text { Frequency } \\
\text { modulation } \\
\text { resistance }\end{array}$ & $\begin{array}{l}\text { To change the voltage on the } \\
\text { two sides of circuit breaker }\end{array}$ & $\begin{array}{l}\text { To generate recovery voltage } \\
\text { through oscillation }\end{array}$ \\
\hline $\mathrm{C}_{0}$ & $\begin{array}{l}\text { Frequency } \\
\text { modulation } \\
\text { capacitor }\end{array}$ & $\begin{array}{l}\text { TB and the amplitude } \\
\text { coefficient }\end{array}$ & \\
\hline $\mathrm{C}_{\mathrm{i}}$ & $\begin{array}{l}\text { Capacitor of } \\
\text { current source }\end{array}$ & \multirow{2}{*}{\multicolumn{2}{|c|}{$\begin{array}{l}\text { To constitute the current source that supplies } 50 \mathrm{~Hz} \text { short-circuit } \\
\text { current }\end{array}$}} \\
\hline $\mathrm{L}_{\mathrm{i}}$ & $\begin{array}{l}\text { Inductance } \\
\text { Resistance }\end{array}$ & & \\
\hline RVDT & $\begin{array}{l}\text { voltage divider } \\
\text { 1000: } 1\end{array}$ & \multicolumn{2}{|c|}{ To measure the charging voltage during the charging of $\mathrm{C}_{\mathrm{u}}$} \\
\hline RCVDT & $\begin{array}{l}\text { Capacitance- } \\
\text { resistance voltage } \\
\text { divider } \\
\text { 1000: } 1\end{array}$ & \multicolumn{2}{|c|}{$\begin{array}{l}\text { To measure the recovery voltage, which is displayed on the } \\
\text { oscilloscope after the signal of the low voltage end is connected to } \\
\text { the console. It is compared with the measured short-circuit current } \\
\text { input into the oscilloscope as a basis for judging whether the test is } \\
\text { successful or not. }\end{array}$} \\
\hline $\operatorname{Rog}$ & Rogowski coil & $\begin{array}{l}\text { To deliver the measured short-cir } \\
\text { integrator Int }\end{array}$ & uit current to the console via the \\
\hline SG & $\begin{array}{l}\text { Spark spherical } \\
\text { gap }\end{array}$ & $\begin{array}{l}\text { To adjust the gap based on } \\
\text { voltage class }\end{array}$ & $\begin{array}{l}\text { SG passes through the high- } \\
\text { voltage discharge electrode of }\end{array}$ \\
\hline TR & Ignition circuit & - & $\begin{array}{l}\text { TR; the voltage source is } \\
\text { triggered. }\end{array}$ \\
\hline $\mathrm{CB}$ & Closing breaker & To introduce the currer & \\
\hline ТВ & Testing breaker & $\begin{array}{l}\text { To be part of the voltage source } \\
\text { and current source } \\
\text { simultaneously }\end{array}$ & $\begin{array}{l}\text { Synchronous acting that } \\
\text { separate the voltage source and }\end{array}$ \\
\hline $\mathrm{AB}$ & Auxiliary breaker & $\begin{array}{l}\text { To quench the arc after zero } \\
\text { crossing in current source }\end{array}$ & the current source \\
\hline
\end{tabular}

Since the capacity of the voltage source was limited in testing, one break of the $126 \mathrm{kV}$ vacuum breaker was used as the testing breaker, and the other as the auxiliary breaker. This not only ensured the consistency of arc duration, but also isolated the current source.

\section{Parameter Configuration of Breaking Capacity Test}

According to standard GB 1984-2014, the breaking capacity will be tested at $10 \%$, $30 \%, 60 \%$ and $100 \%$ rated short-circuit current. In our case, the test was performed at the short-circuit current of $4 \mathrm{kA}, 12 \mathrm{kA}, 24 \mathrm{kA}$ and $40 \mathrm{kA}$, respectively. Thus the parameters of current source and voltage source were configured.

As the current source operates, the capacitance $\mathrm{C}_{\mathrm{i}}$ discharges to the inductor $\mathrm{L}_{\mathrm{i}}$ and the circuit resistance (primarily the contact resistance and line resistance with negligible value). At this time, the arc voltage in the vacuum is very low and exerts negligible influence on the circuit. Thus the relationship between the discharge current of the current source and the charging voltage $\mathrm{U}_{1}$ is described as

$$
\begin{array}{r}
\mathrm{i}_{1}=\mathrm{I}_{1 \mathrm{~m}} \sin \omega_{1} \mathrm{t} \\
\omega_{1}=2 \pi \mathrm{f}_{1} \\
\mathrm{I}_{1 \mathrm{~m}}=\frac{\mathrm{U}_{1}}{\omega_{1} \mathrm{~L}_{\mathrm{i}}}=\mathrm{U}_{1} \sqrt{\frac{\mathrm{C}_{\mathrm{i}}}{\mathrm{L}_{\mathrm{i}}}}
\end{array}
$$


Where $\mathrm{I}_{1 \mathrm{~m}} \longrightarrow$ Effective value of the first half-wave of discharge current (A);

$\omega_{1} \_$Angular frequency of current of current source $(\mathrm{rad} / \mathrm{s})$;

$\mathrm{f}_{1}-$ Oscillation frequency of current of current source, i.e., power frequency;

$\mathrm{L}_{\mathrm{i}}$ - Inductance of discharge current $(\mathrm{H})$;

$\mathrm{C}_{\mathrm{i}} \longrightarrow$ Discharge capacitance of current source $(\mathrm{F})$.

From (3) the relationship between output current of each branch and the charging voltage $U_{1}$ is obtained:

$$
\mathrm{U}_{1}=\sqrt{2} \mathrm{k} \omega_{1} \mathrm{~L}_{\mathrm{i}} \mathrm{I}_{1}
$$

Where $\mathrm{k}$ is current attenuation ratio taken as 1.1

The capacitance of each capacitor stack is about $60000 \mu \mathrm{F}$. The stack is composed of 96 $10000 \mu \mathrm{F}$ electrolytic capacitors arranged parallel in 4 strings with 24 capacitors in each string. To make the actual oscillation frequency close to the power frequency of $50 \mathrm{~Hz}$, the inductance of each coil was set as $0.17 \mathrm{mH}$, and the actual oscillation frequency was $49.83 \mathrm{~Hz}$.

The discharge current and the number of stacks are shown in Table 2.

Table 2. Voltage of the Capacitor and the Circuit Current

\begin{tabular}{c|c|c|c|c|c|c|c}
\hline \multicolumn{2}{c}{ Discharge current $I_{1} /$ Effective value } & \multicolumn{5}{c}{ Charging voltage $\mathrm{U}_{1} / \mathrm{V}$} \\
\hline \multirow{2}{*}{ Class } & \multirow{2}{*}{ Value/kA } & \multirow{2}{*}{ Percentage/\% } & \multicolumn{5}{c}{ Number of stacks } \\
\cline { 4 - 8 } & & & 1 & 2 & 3 & 4 & 5 \\
\hline \multirow{3}{*}{$40 \mathrm{kA}$} & 4 & 30 & $\underline{996}$ & 498 & 332 & 249 & 199 \\
\cline { 2 - 8 } & 24 & 60 & - & $\underline{996}$ & 664 & 498 & 398 \\
\cline { 2 - 8 } & 40 & 100 & - & - & - & $\underline{830}$ & 664 \\
\hline
\end{tabular}

High-voltage charging scheme was chosen so as to reduce the impact of arc voltage on the discharge current. In this paper, the charging scheme of the current source was generally based on the underlined data.

The voltage source charges the LC oscillator circuit with zero input, and the discharge process is similar to that of current source, i.e.,

$$
\begin{array}{r}
\omega_{2}=2 \pi \mathrm{f}_{2} \\
\mathrm{I}_{2 \mathrm{~m}}=\mathrm{U}_{2} \sqrt{\frac{\mathrm{C}_{\mathrm{u}}}{\mathrm{L}_{\mathrm{u}}}}
\end{array}
$$

Where $\omega_{2}-$ Angular frequency of current of voltage source $(\mathrm{rad} / \mathrm{s})$;

$\mathrm{f}_{2}-$ Oscillation frequency of current of voltage source $(\mathrm{Hz})$;

$\mathrm{I}_{2 \mathrm{~m}} \longrightarrow$ Peak of pull-in current (A);

$\mathrm{U}_{2} \longrightarrow$ Charging voltage of voltage source (V);

$\mathrm{C}_{\mathrm{u}} \longrightarrow$ Capacitance of voltage source $(\mathrm{F})$;

$\mathrm{L}_{\mathrm{u}}$ - Inductance of voltage source $(\mathrm{H})$.

The transient peak recovery voltage $u_{c}$ expected at the testing breaker is expressed as

$$
\mathrm{u}_{\mathrm{c}}=\frac{1}{\mathrm{n}} \mathrm{k}_{\mathrm{af}} \mathrm{k}_{\mathrm{u}} \mathrm{k}_{\mathrm{pp}} \sqrt{\frac{2}{3}} \mathrm{U}_{\mathrm{r}}
$$

Where $\mathrm{n} —$ number of breaks, which is 2 ; 
$\mathrm{k}_{\mathrm{u}}$ Comprehensive coefficient considering attenuation effect and effect of unbalanced voltage, taken as 1.1;

$\mathrm{U}_{\mathrm{r}}$ - Rated voltage, taken as $126 \mathrm{kV}$.

Since the voltage source only produces single-frequency oscillation, the transient recovery voltage values were preset by the four-parameter method in standard GB 19842014, as shown in Table 3.

Table 3. Standard Values of TRV

\begin{tabular}{ccccc}
\hline Percent break & $100 \%$ & $60 \%$ & $30 \%$ & $10 \%$ \\
\hline First-pole-to-clear factor $\mathrm{k}_{\mathrm{pp}}$ & 1.3 & 1.3 & 1.3 & 1.5 \\
Amplitude coefficient $\mathrm{k}_{\mathrm{af}}$ & 1.4 & 1.5 & 1.54 & $0.9 \times 1.7$ \\
First reference voltage $\mathrm{u}_{1} / \mathrm{kV}$ & 100 & 100 & - & - \\
Time to reach $\mathrm{u}_{1} \mathrm{t}_{1} / \mu \mathrm{s}$ & 50 & 33 & - & - \\
Transient recovery voltage $\mathrm{U}_{\mathrm{c}} / \mathrm{kV}$ & 188 & 201 & 206 & 236 \\
Time to reach peak $\mathrm{t}_{2}{\text { or } \mathrm{t}_{3} / \mu \mathrm{s}}$ & 200 & 198 & 41 & 34 \\
\hline
\end{tabular}

To ensure the equivalence of the synthetic circuit to the actual circuit, the current $\mathrm{I}_{1 \mathrm{~m}}$ of current source should be correlated to the current $\mathrm{I}_{2 \mathrm{~m}}$ of voltage source by the following formula:

$$
\frac{I_{1 \mathrm{~m}}}{\mathrm{I}_{2 \mathrm{~m}}}=\frac{\omega_{2}}{\omega_{1}}=\frac{\mathrm{f}_{2}}{\mathrm{f}_{1}}
$$

That is, after the voltage source is triggered, the variation rate of current in the testing breaker should be equal to that during current zero crossing in actual grid.

To prevent current distortion caused by the superposition of power-frequency current and pull-in current during arc ignition, the frequency $\mathrm{f}_{2}$ of the pull-in current should be high enough. Moreover, to make it easier to adjust the circuit, frequency $\mathrm{f}_{2}$ of the pull-in current should be lower than the fundamental frequency of transient recovery voltage.

Thus the frequency of the pull-in frequency should be in the following range:

$$
250 \mathrm{~Hz}<\mathrm{f}_{2}<1000 \mathrm{~Hz}
$$

The values of capacitance $C_{u}$ and inductance $L_{u}$ of voltage source should satisfy

$$
\left\{\begin{array}{l}
\mathrm{C}_{\mathrm{u}}=\frac{\mathrm{I}_{2 \mathrm{~m}}}{\mathrm{U}_{\mathrm{m}} \omega_{2}} \\
\mathrm{~L}_{\mathrm{u}}=\frac{1}{\omega_{2}^{2} \mathrm{C}_{\mathrm{u}}}
\end{array}\right.
$$

After current zero crossing and quenching of arc, the expected transient recovery voltage can be obtained by adjusting the frequency modulation capacitance and frequency modulation resistance. The voltage oscillates with frequency $f_{0}$ :

$$
\mathrm{f}_{0}=\frac{1}{2 \pi \sqrt{\frac{\mathrm{C}_{0} \mathrm{C}_{\mathrm{u}}}{\mathrm{C}_{0}+\mathrm{C}_{\mathrm{u}}} \mathrm{L}_{\mathrm{u}}}}
$$

where $\mathrm{C}_{0}$ is the frequency modulation capacitance $(\mathrm{F})$ of voltage source, which is far smaller than $\mathrm{C}_{\mathrm{u}}$, i.e., 


$$
\mathrm{f}_{0}=\frac{1}{2 \pi \sqrt{\mathrm{C}_{0} \mathrm{~L}_{\mathrm{u}}}}
$$

Thus

$$
C_{0}=\frac{1}{\left(2 \pi f_{0}\right)^{2} L_{u}}
$$

As attenuation occurs in the oscillator circuit, the actual attenuation must be larger if the arc voltage is considered. During the testing of vacuum breaker, breaking usually takes place at the first half-wave, and the actual frequency modulation resistance $\mathrm{R}_{0}$ is

$$
\mathrm{R}_{0}=4 \mathrm{~L}_{\mathrm{u}} \mathrm{f}_{0} \ln \left(\frac{1}{\mathrm{k}_{\mathrm{af}}-1}\right)
$$

Thus the parameters of voltage source are listed in Table 4.

Table 4. Parameters of the Voltage Source Circuit

\begin{tabular}{cccccc}
\hline Percent break & $\mathrm{L}_{\mathrm{u}} / \mathrm{mH}$ & $\mathrm{C}_{\mathrm{u}} / \mu \mathrm{F}$ & $\mathrm{R}_{0} / \Omega$ & $\mathrm{C}_{0} / \mu \mathrm{F}$ & $\mathrm{U}_{2} / \mathrm{kV}$ \\
\hline $10 \%$ & 557.4 & 0.545 & 17128 & 0.000311 & 100 \\
$30 \%$ & 185.8 & 0.545 & 4580 & 0.00136 & 100 \\
$60 \%$ & 92.9 & 1.091 & 592 & 0.0515 & 80 \\
$100 \%$ & 46.4 & 2.182 & 391 & 0.103 & 70 \\
\hline
\end{tabular}

The time sequence of acting of switches in the synthetic testing is shown in Figure 2.

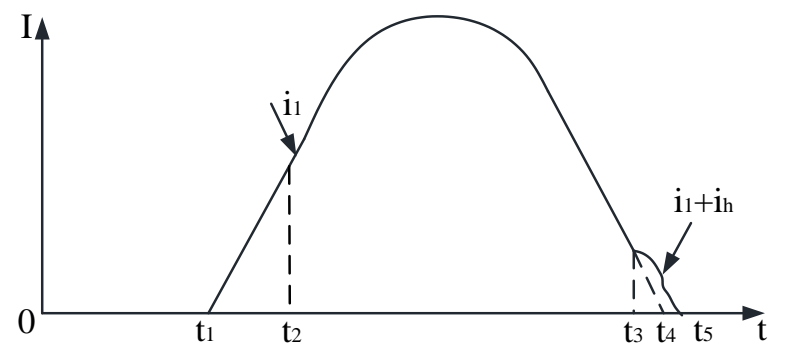

$\mathrm{t}_{1}$ - The moment of closing $\mathrm{CB}$;

$\mathrm{t}_{2}$ - The moment of separation of the contactors of $\mathrm{AB}$ and $\mathrm{TB}$;

$\mathrm{t}_{3}$ - The moment of supplying the current;

$\mathrm{t}_{4}$ - The moment of current breaking by $\mathrm{AB}$;

$\mathrm{t}_{5}$ - The moment of zero crossing in TB

Figure 2. Moment Of Acting of the Switches in the Synthetic Testing 
The flow chart of Weil synthetic circuit is shown in Figure 3.

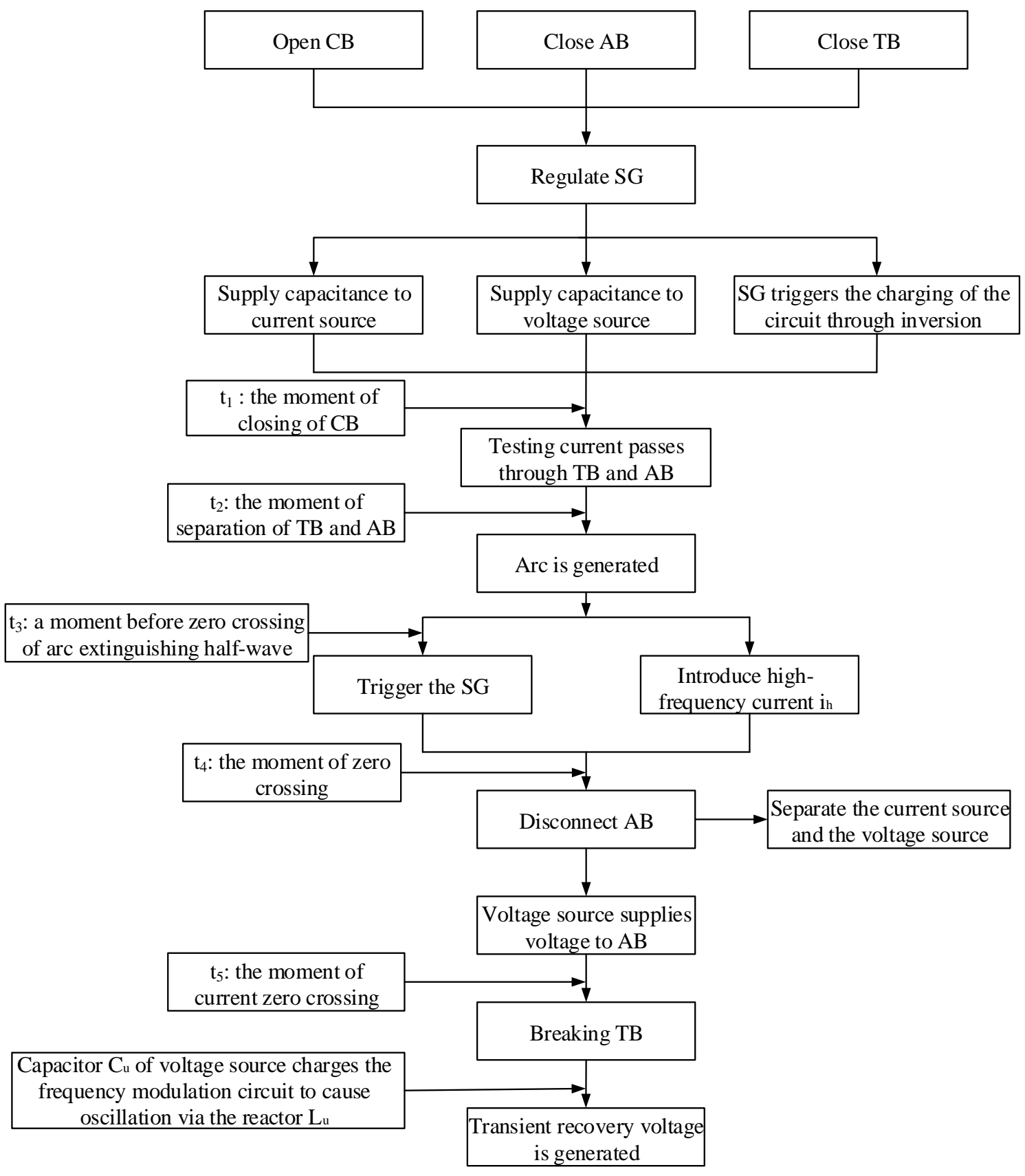

Figure 3. Flow Chart of Weil Synthetic Circuit

After the configuration of circuit parameters, the accurate input time of the switches is crucial to successful testing. The current source provides the oscillating current with power frequency of $50 \mathrm{~Hz}$. Then the minimum arc duration is $6 \mathrm{~cm}$, and

$$
\mathrm{t}_{5}-\mathrm{t}_{2}=6000
$$

As the pull-in current passes through TB, the time of TB being supplied by voltage source alone is longer than that of significant variation of arc voltage. 


$$
\begin{aligned}
& \mathrm{t}_{5}-\mathrm{t}_{3}=\frac{1}{2 \mathrm{f}_{2}} \\
& 200<\mathrm{t}_{5}-\mathrm{t}_{4}<500
\end{aligned}
$$

The trigger time of $\mathrm{SG}$ is mainly related to the time delay of the trigger circuit. Previous tests show that the trigger time stabilizes at $100 \mu \mathrm{s}$, and $10 \%$ error is acceptable.

On the time axis, SG is triggered at $100000 \mu$ s. Thus, starting from the zero time point, the time delay of each trigger signal is shown in Table 5.

Table 5. Time Delay of the Trigger Signals in the Synthetic Experience

\begin{tabular}{cccc}
\hline Percent break & $\begin{array}{c}\text { Time delay of trigger } \\
\text { of } \mathrm{CB} / \mu \mathrm{s}\end{array}$ & $\begin{array}{c}\text { Time delay of trigger of TB } \\
\text { and AB } / \mu \mathrm{s}\end{array}$ & $\begin{array}{c}\text { Time delay of trigger } \\
\text { of SG } / \mu \mathrm{s}\end{array}$ \\
\hline $10 \%$ & 73500 & 69000 & 99000 \\
\hline $20 \%$ & 73500 & 69000 & 98500 \\
\hline $30 \%$ & 73500 & 69500 & 98700 \\
\hline $40 \%$ & 73500 & 69500 & 98100 \\
\hline
\end{tabular}

\section{Result and Analysis}

The result of testing of $126 \mathrm{kV}$ vacuum circuit breaker is shown in Table 6.

\begin{tabular}{|c|c|c|c|c|c|c|}
\hline Test & $\begin{array}{l}\text { Testing method } \\
(\mathrm{O} / \mathrm{O}, \mathrm{C} / \mathrm{C})\end{array}$ & $\begin{array}{c}\text { Breaking } \\
\text { current } \\
(\mathrm{kA})\end{array}$ & $\begin{array}{c}\text { Arc } \\
\text { duration(ms) }\end{array}$ & $\begin{array}{c}\text { Transient } \\
\text { recovery } \\
\text { voltage }(\mathrm{kV})\end{array}$ & $\begin{array}{c}\text { First } \\
\text { reference } \\
\text { voltage } \\
(\mathrm{kV}) \\
\end{array}$ & Result \\
\hline \multirow{4}{*}{$\mathrm{T} 10$} & $\mathrm{O}$ & 4 & 5.8 & 236 & - & Failed \\
\hline & $\mathrm{O}$ & 4 & 6.8 & 236 & - & Success \\
\hline & $\mathrm{CO}$ & 4 & 8.7 & 237 & - & Success \\
\hline & $\mathrm{O}-0.3 \mathrm{~s}-\mathrm{CO}$ & 4 & 11.0 & 237 & - & Success \\
\hline \multirow{4}{*}{ T30 } & $\mathrm{O}$ & 12 & 5.6 & 205 & - & Failed \\
\hline & $\mathrm{O}$ & 12 & 7.8 & 206 & - & Success \\
\hline & $\mathrm{O}$ & 14.5 & 8.0 & 206 & - & Success \\
\hline & $\mathrm{O}-0.3 \mathrm{~s}-\mathrm{CO}$ & 14.6 & 11.2 & 205 & - & Success \\
\hline \multirow{3}{*}{ T60 } & $\mathrm{O}$ & 24.2 & 8.6 & 205 & 100 & Success \\
\hline & $\mathrm{O}$ & 24 & 12.0 & 206 & 100 & Success \\
\hline & $\mathrm{O}-0.3 \mathrm{~s}-\mathrm{CO}$ & 24.1 & 10.3 & 206 & 101 & Success \\
\hline \multirow{3}{*}{$\mathrm{T} 100 \mathrm{~s}$} & $\mathrm{O}$ & 40 & 8.9 & 189 & 100 & Success \\
\hline & $\mathrm{O}$ & 40 & 10.4 & 189 & 100 & Success \\
\hline & $\mathrm{O}-0.3 \mathrm{~s}-\mathrm{CO}$ & 40 & 12.3 & 191 & 101 & Success \\
\hline
\end{tabular}

Table 6. Esult of Short Circuit Breaking Test

No abnormalities were observed during testing. Re-ignition occurred in T10 and T30 at arc duration of $5.8 \mathrm{~ms}$ and $5.6 \mathrm{~ms}$, respectively, indicating failed breaking.

The experimental result was consistent with theoretical analysis. That is, the breaking capacity decreased significantly when the arc duration was shorter than $6 \mathrm{~ms}$. At this time, the probability of re-ignition increased with decreased arc quenching ability. When the arc duration was longer than $6 \mathrm{~ms}$, circuit breaking test T10, T30, T60 and T100s was performed three times, respectively, and all of them succeeded. Thus the circuit breaker satisfies the national standard on circuit breaking under $126 \mathrm{kV}$ voltage class and therefore is qualified for grid integration. 
The contactor of the arc extinguishing chamber after failure of circuit breaking is shown in Figure 4.
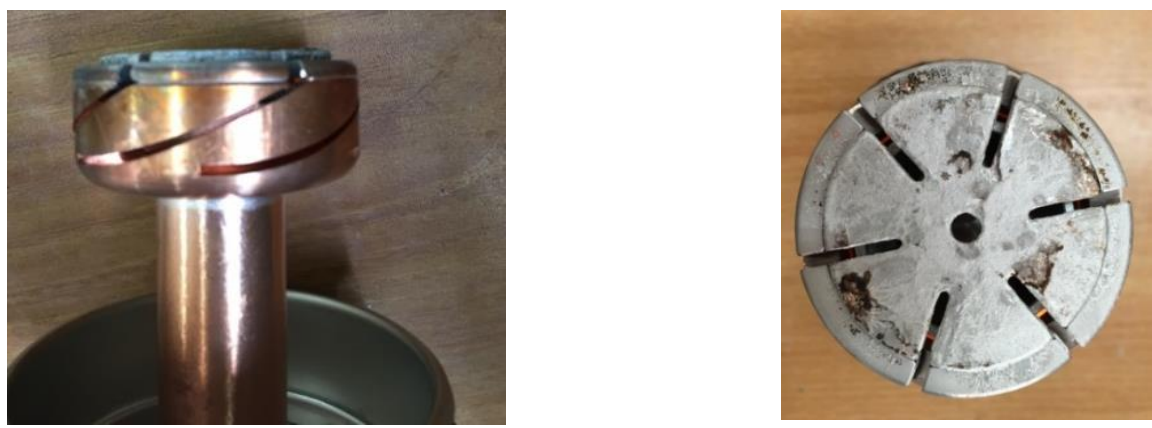

Figure 4. Arc Extinguishing Chamber Contactor After Circuit Breaking Failure

To test the maximum breaking capacity, T100a test was performed in the same way as T100s, and the testing results are shown in Table 7.

Table 7. Results of T100a Test

\begin{tabular}{c|c|c|c|c|c}
\hline \multirow{3}{*}{ Test } & $\begin{array}{c}\text { Testing method } \\
(\mathrm{O} / \mathrm{O}, \mathrm{C} / \mathrm{C})\end{array}$ & $\begin{array}{c}\text { Breaking } \\
\text { current }(\mathrm{kA})\end{array}$ & $\begin{array}{c}\text { Arc duration } \\
(\mathrm{ms})\end{array}$ & $\begin{array}{c}\text { Transient } \\
\text { recovery voltage } \\
(\mathrm{kV})\end{array}$ & Result \\
\hline \multirow{3}{*}{ T100a } & $\mathrm{O}$ & 40 & 9.8 & 196 & Failed \\
\cline { 2 - 6 } & $\mathrm{O}$ & 40 & 12.1 & 195 & Succeed \\
\cline { 2 - 6 } & $\mathrm{O}$ & 50 & 11.8 & 199 & Failed \\
\cline { 2 - 6 } & $\mathrm{O}$ & 50 & 11.8 & 196 & Succeed \\
\hline
\end{tabular}

It can be seen from Table 7 that when the arc duration is $9.8 \mathrm{~ms}$ and the transient recovery voltage is $196 \mathrm{kV}$, re-ignition occurs and the breaking fails; when the arc duration is $12.1 \mathrm{~ms}$ and the transient recovery voltage is $195 \mathrm{kV}$, the circuit breaking succeeds. When the breaking current increases to $50 \mathrm{kV}$, arc duration is $11.8 \mathrm{~ms}$ and transient recovery voltage is $199 \mathrm{kV}$, circuit breaking fails. However, with other conditions being constant, the circuit breaking succeeds when the transient recovery voltage is $196 \mathrm{kV}$. Thus the $126 \mathrm{kV}$ vacuum circuit breaker can interrupt the $50 \mathrm{kV}$ shortcircuit current in case of fault.

To conclude, $126 \mathrm{kV}$ vacuum circuit breaker satisfies the national standard and the design is reasonable.

\section{Summary}

Breaking capacity test was performed for the $126 \mathrm{kV} / 2500 \mathrm{~A} / 40 \mathrm{kA}$ vacuum circuit breaker according to national standard GB 1984-2014. To adapt to the requirements on double breaks and high voltage, the Weil synthetic circuit by Dalian University of Technology was optimized. Basically no abnormalities were observed in testing, and the short-circuit current breaking capacity of the vacuum circuit breaker increased linearly. Result shows that the $126 \mathrm{kV} / 2500 \mathrm{~A} / 40 \mathrm{kA}$ vacuum circuit breaker developed by BENEFO satisfies the national standard, and the design is reasonable and eligible for grid integration. This also demonstrates the feasibility of raising the voltage class of multibreak vacuum circuit breakers.

However, the test with long arc duration failed due to limited testing conditions and the low energy of arc circuit in spite of the strong arch extinguishing capacity of SG in the 
vacuum circuit breaker. The testing interval of arc duration was only $6-13 \mathrm{~ms}$ in this paper, but actually the maximum arc duration may be over $13 \mathrm{~ms}$.

\section{References}

[1] J. Wang, W. Wu, Y. Wei and W. Liu, Vacuum Switch, China Machine Press, Beijing (1983).

[2] T. Wenzel and T. Leibfried, IEEE Transactions on Power Delivery, vol. 1, no. 27, (2012).

[3] R. B. Shores and V. E. Pilips, IEEE Transactions on Power Apparatus and Systems, vol. 5, no. 94, (1975).

[4] X. Lin, X. Ma and H. Li, High Voltage Apparatus, vol. 9, no.51, (2015).

[5] S Giere, HC Karner and H Knobloch, "IEEE Transactions on Dielectrics and Electrical Insulation, vol. 1, no. $8,(\mathbf{2 0 0 1})$.

[6] S. Fan, P. Gu, J.Wang and Y.Wang, Electrotechnical Application, vol. 4, no. 93, (1993).

[7] S. Shu, J. Ruan and D. Huang, High Voltage Engineering, vol. 8, no. 40, (2014).

[8] L. Liu and J. Zhuang, Proceedings of the CSEE, vol. 6, no. 34, (2014).

\section{Authors}

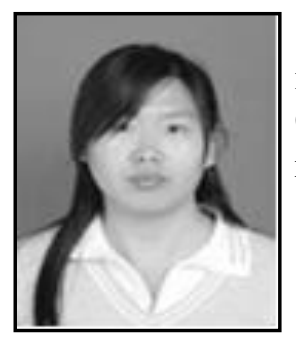

XIE Jiuming, a PhD candidate in Yanshan University, now works in Central Research Institute of Tianjin Benefo Machinery Equipment Group Co., LTD. The main research direction is mechanical reliability of electrical equipment. 